\title{
Mudanças relacionadas ao amaciamento da graviola durante a maturação pós-colheita
}

\author{
Maria Auxiliadora Coêlho de Lima ${ }^{(1)}$, Ricardo Elesbão Alves ${ }^{(2)}$ e Heloísa Almeida Cunha Filgueiras ${ }^{(2)}$
}

\begin{abstract}
(1)Embrapa Semi-Árido, Caixa Postal 23, CEP 56300-970 Petrolina, PE. E-mail: maclima@cpatsa.embrapa.br (2)Embrapa Agroindústria Tropical, Caixa Postal 3761, CEP 60511-110 Fortaleza, CE. E-mail: elesbao@cnpat.embrapa.br, filgueiras@agroserv.agropolis.fr
\end{abstract}

\begin{abstract}
Resumo - Este trabalho teve por objetivo avaliar mudanças físicas, químicas e bioquímicas relacionadas ao amaciamento de graviola (Annona muricata L.) Crioula durante a maturação. Os frutos foram colhidos no estádio de maturidade fisiológica, em plantas cultivadas na Estação Experimental da Embrapa Agroindústria Tropical, em Pacajus, Ceará, armazenados a 26,3 $\pm 0,6^{\circ} \mathrm{C}$ e $88 \pm 12 \%$ de umidade relativa, durante 1, 2, 3, 4 e 5 dias. Utilizou-se o delineamento experimental inteiramente casualizado, com quatro repetições. As variáveis analisadas foram: perda de massa, amido, pectina total e solúvel, e atividades das enzimas amilase, pectinametilesterase, poligalacturonase, alfa-galactosidases e beta-galactosidases. Não houve variação significativa no conteúdo de pectina solúvel. Após cinco dias, a perda de massa atingiu 5\%, mas não promoveu murcha dos frutos. As reduções nos conteúdos de amido e de pectina total coincidiram com período de expressiva atividade, respectivamente, das enzimas amilase e da poligalacturonase e beta-galactosidase de parede celular. As modificações mais acentuadas no conteúdo de amido, de pectina total, na solubilização de pectinas e na atividade das enzimas amilase, pectinametilesterase, poligalacturonase e beta-galactosidase de parede celular ocorreram no período do segundo ao quarto dia após a colheita.
\end{abstract}

Termos para indexação: Annona muricata, amido, Annonaceae, enzimas hidrolíticas, pectina.

\section{Changes related to softening of soursop during postharvest maturation}

\begin{abstract}
This work aimed to evaluate the physical, chemical and biochemical changes related to softening during maturation of Crioula soursop fruit (Annona muricata L.). Fruits were harvested at the physiological maturity stage from plants grown at Embrapa Agroindústria Tropical Experimental Station, in Pacajus, CE, Brazil, and were stored at $26.3 \pm 0.6^{\circ} \mathrm{C}$ and $88 \pm 12 \%$ relative humidity, during $1,2,3,4$ and 5 days. A completely randomized design was used with four replicates. The following variables were evaluated: weight loss; starch content; total and soluble pectin content and enzymatic activity of amylase, pectin methylesterase, polygalacturonase and alfa- and beta-galactosidases. There was no significant variation in the soluble pectin content. Weight loss reached $5 \%$ in the fifth day, without causing fruit shriveling. Reductions on starch and on total pectin contents occurred in the period of great enzymatic activity, respectively, of amylase and of polygalacturonase, and cell wall beta-galactosidase. The most significant changes on the contents of starch and total pectin, on pectin solubilization and on the activity of the enzymes amylase, pectin methylesterase, polygalacturonase and cell wall beta-galactosidase occurred from the second to the fourth day after harvest.
\end{abstract}

Index terms: Annona muricata, starch, Annonaceae, hydrolytic enzymes, pectin.

\section{Introdução}

Annona spp. abrange mais de 50 espécies, das quais apenas a graviola (A. muricata), a pinha (A. squamosa), a condessa (A. reticulata), a cherimóia (A. cherimola) e a atemóia (A. squamosa x A. cherimola) possuem importância econômica. No Brasil, as áreas cultivadas com pinha e graviola são as mais representativas (SãoJosé et al., 2000).
Em relação à graviola, apesar da escassez de informações estatísticas oficiais e atualizadas, São-José et al. (2000) citam que as áreas produtoras estão instaladas principalmente nas regiões litorâneas e semiáridas do Nordeste, onde predomina a graviola Nordestina ou Crioula ou Comum. Esse material genético possui frutos cordiformes, de casca verde-escura com terminações estilares (pseudo-acúleos) proeminentes e numerosos, massa entre 1,5 e $3 \mathrm{~kg}$, polpa macia e sabor de doce a subácido (Ramos, 1999). 
A produção que era totalmente destinada para a agroindústria, hoje tem um volume significativo comercializado como fruta fresca, especialmente nos mercados de São Paulo, Rio de Janeiro, Recife, Salvador, Fortaleza e Brasília (São-José et al., 2000). No entanto, a alta perecibilidade do fruto e o curto período de conservação após a colheita (Aziz \& Yusof, 1994) respondem por altos índices de perdas (Mosca et al., 1997).

Qualquer tentativa de redução das perdas pós-colheita e de conservação da qualidade da graviola, por um período compatível com a demanda do mercado, requer o conhecimento do metabolismo do fruto durante o amadurecimento. Tal conhecimento possibilitaria propor estratégias e tecnologias que reduzissem a velocidade das transformações bioquímicas, sem prejuízo da qualidade.

Existem poucos estudos sobre as mudanças póscolheita na graviola; os trabalhos, em geral, caracterizam alterações na cor da casca e no conteúdo de açúcares, de ácidos orgânicos e de compostos fenólicos da polpa (Aziz \& Yusof, 1994; Mosca et al., 1997). O conhecimento de outras modificações, como as relacionadas à firmeza e às atividades de enzimas, principalmente as hidrolíticas, envolvidas no amadurecimento, ainda é escasso.

Este trabalho teve por objetivo caracterizar alterações de natureza física, química e bioquímica, associadas ao amaciamento da graviola durante a maturação pós-colheita.

\section{Material e Métodos}

Os frutos utilizados neste trabalho provieram da Estação Experimental da Embrapa Agroindústria Tropical, localizada em Pacajus, CE, de pomar de gravioleiras Crioula, com quatro anos de idade, cultivadas em espaçamento $5 \times 4 \mathrm{~m}$.

As graviolas foram colhidas na maturidade fisiológica, reconhecida por meio da maior separação entre as terminações estilares e da perda de consistência destas estruturas.

Após a colheita, os frutos foram transportados para o Laboratório de Fisiologia e Tecnologia Pós-Colheita, da Embrapa Agroindústria Tropical, em Fortaleza, CE, onde foram submetidos à seleção, com base na sanidade e uniformidade de maturação e formato. Os frutos foram, então, armazenados a $26,3 \pm 0,6^{\circ} \mathrm{C}$ e $88 \pm 12 \%$ de umidade relativa (UR), e avaliados aos 1, 2, 3, 4, e 5 dias após a colheita, quanto atingiram a condição ótima para consumo. As variáveis analisadas foram: perda de massa; teor de amido, pectina total e solúvel; porcetagem de solubilização da pectina; e atividade das enzimas amilase, pectinametilesterase, poligalacturonase, alfagalactosidases e beta-galactosidases.

A perda de massa (\%) foi obtida por meio da diferença entre a massa do fruto no dia da colheita e na data da avaliação, tendo-se utilizado balança semi-analítica.

A extração do amido foi realizada por hidrólise ácida, conforme Association of Official Agricultural Chemists (1992). A partir do filtrado obtido, determinou-se o conteúdo de açúcares redutores, por meio do ácido 3,5-dinitrosalicílico (DNS), segundo Miller (1959), com a multiplicação dos resultados pelo fator 0,9 , para se obter o rendimento da transformação da sacarose em glicose, na hidrólise.

Na determinação da atividade da amilase ( $\mu$ mol de maltose $\mathrm{g}^{-1} \mathrm{~min}^{-1}$ ), a extração e o doseamento seguiram o método descrito por Bernfeld (1955), modificado por Khader (1992).

As pectinas totais e solúveis (g $100 \mathrm{~g}^{-1}$ ) foram extraídas segundo procedimento descrito por McReady \& McComb (1952). Para extração da pectina total, ajustouse o $\mathrm{pH}$ para 11,5, com posterior repouso durante $30 \mathrm{~min}$. A seguir, o $\mathrm{pH}$ foi ajustado para 5,0-5,5, para permitir as condições ideais de hidrólise por meio da pectinase (E.C.3.2.1.15) de Aspergillus niger, $1 \mathrm{U} \mathrm{mg}^{-1}$. As leituras foram realizadas em espectrofotômetro, a $520 \mathrm{~nm}$, segundo Blumenkrantz \& Asboe-Hansen (1973).

A porcentagem de solubilização de pectina foi obtida pelo quociente entre o conteúdo de pectina solúvel e o da pectina total.

A extração e a determinação da atividade da pectinametilesterase (PME, Unidade de Atividade Enzimática $\mathrm{g}^{-1} \mathrm{~min}^{-1}$ ) seguiram recomendação de Jen \& Robinson (1984). A taxa de desmetilação do extrato foi medida por titulação, com $\mathrm{NaOH} 0,025 \mathrm{M}$, tendo-se mantido o pH em 7 por $10 \mathrm{~min}$. Uma unidade de atividade enzimática (UAE) foi definida como a quantidade de enzima capaz de catalisar a desmetilação de pectina correspondente ao consumo de $1 \mathrm{nmol}$ de $\mathrm{NaOH}$ por $10 \mathrm{~min}$.

A técnica de extração da poligalacturonase (PG, $\mathrm{UAE} \mathrm{g}^{-1} \mathrm{~min}^{-1}$ ) foi a mesma usada para a PME (Jen \& Robinson, 1984). O extrato foi incubado com solução de ácido poligalacturônico $0,25 \%$, em tampão acetato de sódio $37,5 \mathrm{mM}, \mathrm{pH} 5$, a $30^{\circ} \mathrm{C}$, por 3 horas. A reação foi interrompida em banho-maria fervente, e os grupos redutores liberados foram determinados pela técnica do DNS (Miller, 1959). Admitiu-se 1 UAE de PG como a quantidade de enzima capaz de catalisar a formação de 1 nmol de grupos redutores por minuto. 
Para a extração de alfa-galactosidases e betagalactosidases (alfa-GAL e beta-GAL, UAE g-1 $\mathrm{min}^{-1}$ ) procedeu-se conforme Kitagawa et al. (1995), e a atividade foi determinada segundo Dey \& Pridham (1969). O sobrenadante obtido da primeira centrifugação $\left(7.000 \mathrm{~g}, 15 \mathrm{~min}, 4^{\circ} \mathrm{C}\right)$ foi utilizado para determinação da atividade enzimática solúvel no citosol, e o resíduo lavado foi ressuspendido e submetido a nova centrifugação $\left(15.000 \mathrm{~g}, 20 \mathrm{~min}, 4^{\circ} \mathrm{C}\right)$. O novo sobrenadante foi submetido à diálise por 24 horas e utilizado para determinação das atividades das enzimas na parede celular. Os extratos foram incubados por $15 \mathrm{~min}$, a $55^{\circ} \mathrm{C}$ (para determinação da atividade da alfa$\mathrm{GAL}$ ) e a $37^{\circ} \mathrm{C}$ (para beta-GAL), em solução dos substratos alfa-para-nitro-D-galactopiranosídeo e betapara-nitro-D-galactopiranosídeo 0,003 M. As leituras foram realizadas em espectrofotômetro, a $400 \mathrm{~nm}$, tendo-se considerado 1 UAE como a quantidade de atividade da enzima que produziu uma mudança de 0,001 unidade de absorbância.

Utilizou-se o delineamento experimental inteiramente casualizado, com cinco tratamentos e quatro repetições, e cada parcela foi constituída por um fruto.

Os dados foram submetidos a análises de variância e, para os casos em que os tratamentos foram significativos, procedeu-se às análises de regressão polinomial. Foram admitidas equações polinomiais de até 3 o grau e coeficientes de determinação superiores a 0,70. Quando estes critérios não foram atendidos, foram representados os valores médios dos tratamentos sem curva de ajuste.

Os valores de perda de massa, expressos em porcentagem, foram analisados após transformação em arc sen $(\mathrm{x} / 100)^{0,5}$. Para representação gráfica, foram utilizadas as médias não transformadas, obtidas a partir da operação inversa à transformação.

\section{Resultados e Discussão}

Nas condições a que os frutos foram submetidos, a perda de massa aumentou progressivamente (Figura 1). Após um dia de armazenamento, a perda era de 0,46\% e, aos cinco dias, atingiu 5,1\%. O período mais crítico ocorreu do segundo para o terceiro dia, quando se registrou a maior perda de massa no intervalo de um dia. Esta resposta confirma observações realizadas em estudos anteriores com graviola 'Morada' (Lima et al., 2003).

Uma das principais conseqüências da perda de água é o prejuízo da aparência do fruto. Segundo Wills et al.
(1998), valores de 5\% são suficientes para promover murcha, enrugamento e perda de consistência na maioria dos frutos e hortaliças. A perda de massa, representada principalmente pela perda de água, também influencia as taxas em que o amaciamento da polpa ocorre e apresenta relação direta com a temperatura de armazenamento (Johnston et al., 2001). Em conjunto, tais efeitos podem comprometer a qualidade e reduzir a vida útil pós-colheita.

Ao final de cinco dias após a colheita, mesmo tendo atingido valores de perda de massa de cerca de $5 \%$, as graviolas não mostraram quaisquer sinais de enrugamento ou murcha. Alguns frutos só exibem estes sinais com perdas de massa maiores. Mosca et al. (1997) destacaram que mesmo perdas de massa de $11 \%$ não resultaram em sinais de murcha em graviola.

O conteúdo de amido decresceu após a colheita, de 10,52 para 1,68 g $100 \mathrm{~g}^{-1}$ (Figura 2). Analisando-se as médias dos dados originais, observa-se que entre o terceiro e o quarto dia houve uma queda mais marcante, correspondente à variação de 5,22 g $100 \mathrm{~g}^{-1}$. Em apenas um dia, a intensa atividade degradativa reduziu o conteúdo de amido de 7,90 para 2,68 g 100 g-1.

A degradação de amido envolve a ação de várias enzimas, inclusive a alfa-amilase, beta-amilase, amido fosforilase e alfa-glicosidase. A ação cooperativa dessas enzimas resulta na liberação inicial de oligossacarídeos e, posteriormente, de maltose, glicose e glicose-1-fosfato (Irving et al., 1999).

A atividade amilásica total, que no primeiro dia após a colheita era de 7,74 $\mu \mathrm{mol}$ de maltose $\mathrm{g}^{-1} \mathrm{~min}^{-1}$, aumentou a partir do segundo dia (Figura 2). O período de maior atividade coincidiu com a maior degradação

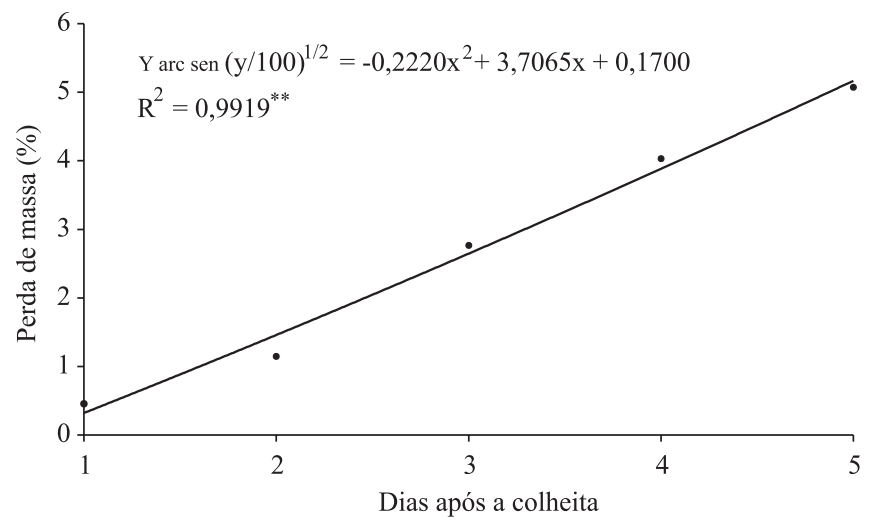

Figura 1. Perda de massa de graviola Crioula, durante a maturação à temperatura ambiente $\left(26,3 \pm 0,6^{\circ} \mathrm{C}\right.$ e $88 \pm 12 \%$ UR). 
do amido. Entre o terceiro e o quarto dia, observou-se incremento de 5,35 $\mu \mathrm{mol}$ de maltose $\mathrm{g}^{-1} \mathrm{~min}^{-1}$. Após o quarto dia, quando os níveis de amido estavam reduzidos a $25 \%$ do conteúdo inicial, a atividade amilásica tendeu à estabilização.

A contribuição das diferentes enzimas envolvidas no processo também varia com o tempo. Em banana, Purgatto et al. (2001) consideraram que a alfa-amilase teve participação importante na degradação inicial do amido e que a beta-amilase contribuiu decisivamente nas etapas posteriores.

Até o terceiro dia após a colheita, observou-se aumento no conteúdo de pectina total de 0,38 para $0,54 \mathrm{~g} 100 \mathrm{~g}^{-1}$ (Figura 3). A partir daí, um rápido decréscimo reduziu o conteúdo para $0,24 \mathrm{~g} 100 \mathrm{~g}^{-1}$, aos quatro dias após a colheita. Ao final do estudo, o conteúdo teve um pequeno aumento.

O conteúdo de pectina solúvel, no entanto, não exibiu alterações significativas durante o período experimental (Figura 3). Porém, as variações no conteúdo de pectina total resultaram em mudanças consideráveis na porcentagem de solubilização de pectinas (Figura 3). Incrementos na solubilização foram observados até o quarto dia após a colheita, quando atingiram $44 \%$.

Em outros frutos tropicais, a solubilização de pectinas, durante o amadurecimento, pode resultar em aumentos nos níveis de poliuronídeos solúveis superiores a 300\% e pode ser acompanhada de elevada perda destes compostos da parede celular (Ali et al., 2004).

Aziz \& Yusof (1994) verificaram redução no conteúdo de pectina total e solúvel, durante o amadurecimento da graviola, ao mesmo tempo em que o fruto amaciava.

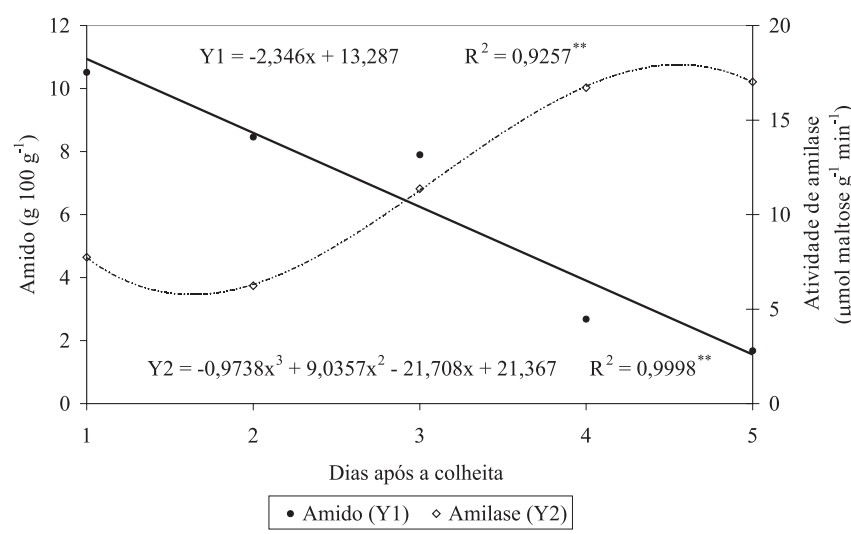

Figura 2. Conteúdo de amido e atividade de amilase de graviola Crioula, durante a maturação à temperatura ambiente (26,3 $\pm 0,6^{\circ} \mathrm{C}$ e $88 \pm 12 \%$ UR).
Esta resposta é comum a outros frutos e se deve provavelmente à quebra de ligações entre as substâncias pécticas e a hemicelulose (Ketsa \& Daengkanit, 1999; Imsabai et al., 2002).

Ali et al. (2004) sugerem que somente as mudanças nas substâncias pécticas não são suficientes para explicar as diferentes taxas de amaciamento dos frutos. Da mesma forma, estas diferenças também não podem ser atribuídas exclusivamente à degradação do amido.

Em geral, as alterações no conteúdo de pectina estão associadas à degradação enzimática. Porém, a conformação estrutural da molécula que está unida, pelo menos parcialmente, por interações não co-valentes, reforça a possibilidade de degradação não-enzimática, influenciada pelo $\mathrm{pH}$ apoplástico, pelos níveis de íons inorgânicos na parede celular, por proteínas nãoenzimáticas, pela porosidade da parede e por barreiras estruturais (Huber et al., 2001).

Durante a maturação, a atividade da PME teve incrementos bastante expressivos (Figura 4). No intervalo de um dia, a atividade da enzima, que inicialmente era de $292 \mathrm{UAE} \mathrm{g}^{-1} \mathrm{~min}^{-1}$, aumentou em sete vezes. Porém, o maior incremento foi observado entre o terceiro e o quarto dia. Ao término do experimento, a atividade foi 23 vezes maior que a inicial.

Essa resposta, contudo, nem sempre é observada. A atividade total da PME pode diminuir, permanecer constante ou aumentar durante a maturação, dependendo do fruto e do método de extração. As mudanças são complicadas, ainda, pela presença de isoformas ou inibidores enzimáticos (Ali et al., 2004). Em alguns casos, tem sido verificada a atividade de PME,

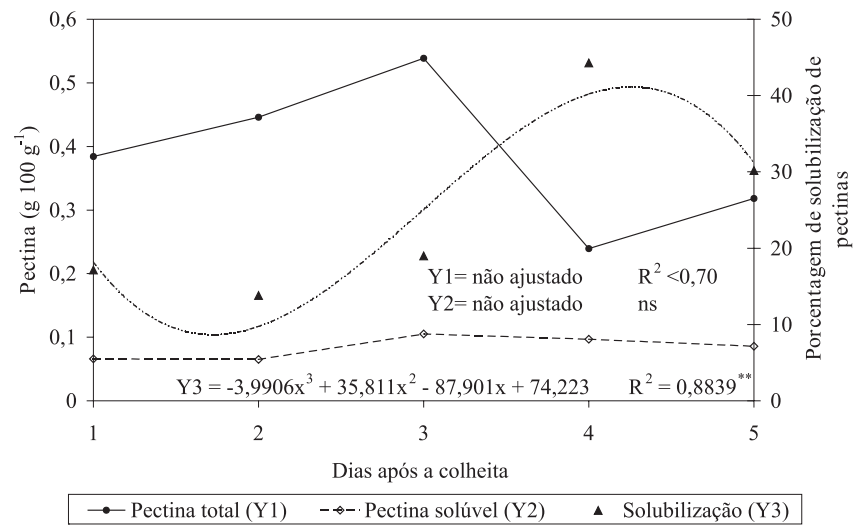

Figura 3. Conteúdo de pectinas e porcentagem de solubilização, em graviola Crioula, durante a maturação à temperatura ambiente $\left(26,3 \pm 0,6^{\circ} \mathrm{C}\right.$ e $88 \pm 12 \%$ UR). 
antes mesmo que a atividade da PG seja detectada (Ketsa \& Daengkanit, 1999).

A importância da PME no amaciamento dos frutos é ampliada, quando se considera que esta enzima pode ajudar direta ou indiretamente a ação de outras, ao criar um ambiente iônico adequado, ou, possivelmente, ao modificar a porosidade da parede celular. Desta forma, favorece o acesso de outras enzimas aos seus substratos potenciais (Ali et al., 2004).

A atividade da PG praticamente não sofreu alterações até o segundo dia (Figura 4). A partir daí, foram observadas mudanças importantes em curto intervalo de tempo. No terceiro dia após a colheita, a atividade atingiu o máximo (47 UAE g-1 $\mathrm{min}^{-1}$ ), tendo diminuído para $17 \mathrm{UAE} \mathrm{g}^{-1} \mathrm{~min}^{-1}$ ao quarto dia, quando se verificou a maior variação. Este período coincidiu com uma queda brusca no conteúdo de pectina total e com a maior solubilização de pectinas (Figura 3), o que indica que a maior parte dos substratos da PG foi imediatamente utilizada, no momento de máxima atividade.

Estudos realizados por Aziz \& Yusof (1994), com graviola, apontaram um incremento na atividade da PG durante o climatério, comparado ao que foi observado no pré-climatério. Morgutti et al. (2005) sugeriram uma relação direta entre a presença de PG e a produção de etileno. Karakurt \& Huber (2003) consideraram que o aumento de atividade da PG, assim como de outras hidrolases, pode ser uma resposta ao incremento da produção de etileno.

À semelhança do que ocorre com a PME, a atividade da PG difere entre espécies. Em alguns casos, foram verificadas altas correlações entre o aumento da

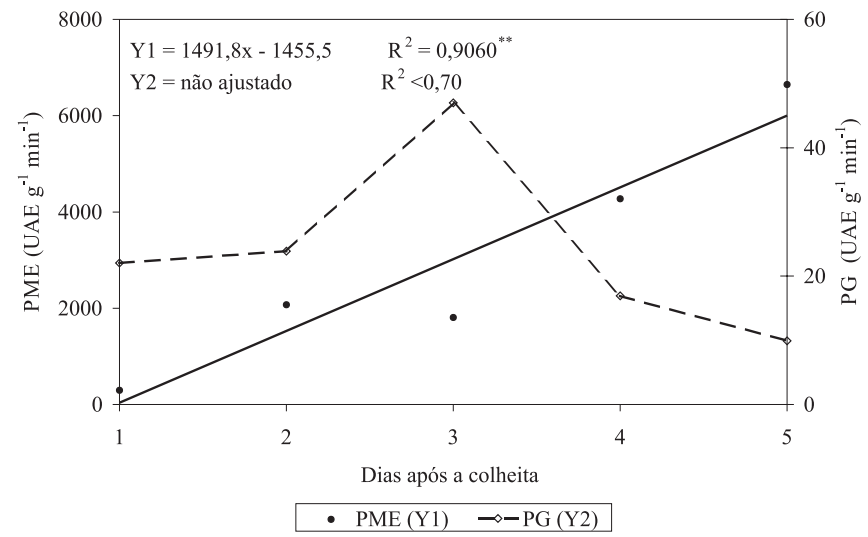

Figura 4. Atividade das enzimas pectinametilesterase (PME) e poligalacturonase (PG) de graviola Crioula, durante a maturação à temperatura ambiente $\left(26,3 \pm 0,6^{\circ} \mathrm{C}\right.$ e $88 \pm 12 \%$ UR). atividade da enzima e a perda de firmeza do fruto (Imsabai et al., 2002; Ali et al., 2004). Em outros, apesar da forte correlação, somente a ação da enzima não deve ser suficiente para promover o amaciamento (Ketsa \& Daengkanit, 1999; Giovannoni, 2001). Outros autores mencionaram, ainda, que mudanças significativas na firmeza de alguns frutos ocorrem mesmo na ausência de relevante atividade de PG e que o acúmulo da enzima ocorre nos estádios finais do amadurecimento (Huber et al., 2001).

As variações nas atividades das alfa-GAL, extraídas do citosol e da parede celular, ocorreram a partir do segundo dia (Figura 5). A atividade da alfa-GAL citosólica aumentou em quatro vezes, do segundo para o terceiro dia após a colheita, quando se observou o valor máximo (1.269 UAE g $\left.{ }^{-1} \mathrm{~min}^{-1}\right)$. A partir daí, verificou-se uma redução de $60 \%$, que se manteve até o quinto dia. Para a alfa-GAL de parede celular, a atividade foi menor, decresceu ao longo do tempo e, a partir do segundo dia após a colheita, representou proporções cada vez maiores da atividade alfagalactosidásica total. Sua importância para o amaciamento da graviola deve, então, ser secundária.

Soh et al. (2006) observaram que a atividade total da alfa-GAL aumentou em seis vezes durante o amadurecimento de mamão, especialmente no período de rápida perda de firmeza.

Alguns trabalhos ressaltam que a atividade das GAL promove alterações em açúcares neutros (como arabinose e galactose), constituintes dos poliuronídeos. A liberação de resíduos desses açúcares neutros das cadeias laterais de poliuronídeos pode estar envolvida

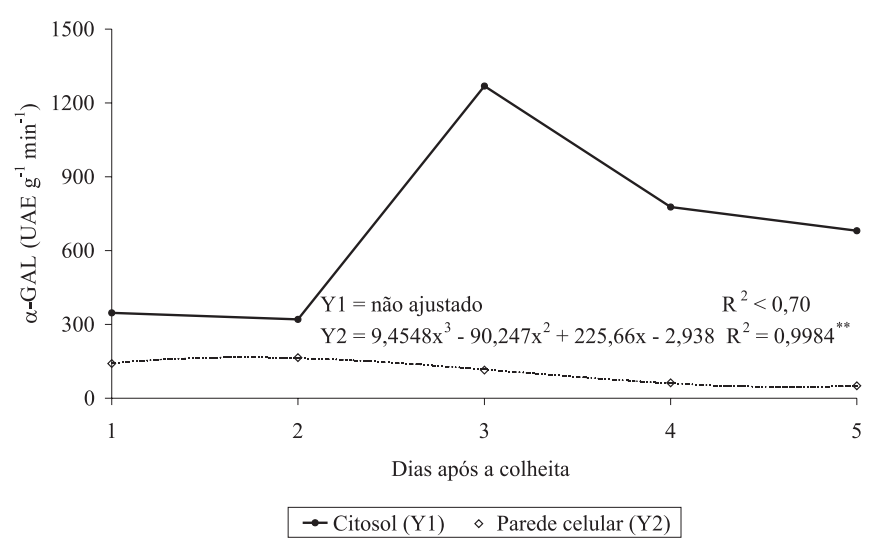

Figura 5. Atividade de alfa-galactosidases ( $\alpha$-GAL), extraídas do citosol e da parede celular, de graviola Crioula, durante a maturação à temperatura ambiente $\left(26,3 \pm 0,6^{\circ} \mathrm{C}\right.$ e $88 \pm 12 \%$ UR). 
na sua solubilização, durante o amaciamento (Gallego \& Zarra, 1998).

Segundo Gross et al. (1995), a suscetibilidade das pectinas às hidrolases aumenta com a remoção de açúcares neutros das cadeias laterais. Porém, diferenças na relação entre a perda de galactose e a solubilização de pectinas indicam que o último processo ocorre em conseqüência do amadurecimento e que o primeiro tem várias funções no metabolismo da parede celular.

As mudanças na atividade das beta-GAL, durante 0 amadurecimento, foram distintas daquelas observadas para as alfa-GAL (Figura 6). A atividade da beta-GAL citosólica, apesar dos valores mais altos, decresceu até $784 \mathrm{UAE} \mathrm{g}^{-1} \mathrm{~min}^{-1}$. Esta resposta indica exportação da enzima para a parede celular, já que a atividade da betaGAL de parede celular aumentou de 140 para $622 \mathrm{UAE} \mathrm{g}^{-1} \mathrm{~min}^{-1}$, no intervalo do primeiro para o quarto dia após a colheita. No quinto dia, a atividade foi reduzida à metade. A proporção da atividade da beta-GAL de parede celular, em relação à atividade beta-galactosidásica total, conseqüentemente, aumentou durante todo o período.

Registros de aumentos na atividade de beta-GAL, durante o amadurecimento, foram feitos por Karakurt \& Huber (2003), Ali et al. (2004) e Mwaniki et al. (2005).

A solubilização de pectinas e a liberação de resíduos galactosil, das galactanas associadas à celulose, poderiam explicar parcialmente o amaciamento (Gallego \& Zarra, 1998). No que se refere à liberação de resíduos galactosil da parede celular, o processo está envolvido, também, na modulação dos níveis de galactose durante o amadurecimento (Gross et al., 1995).

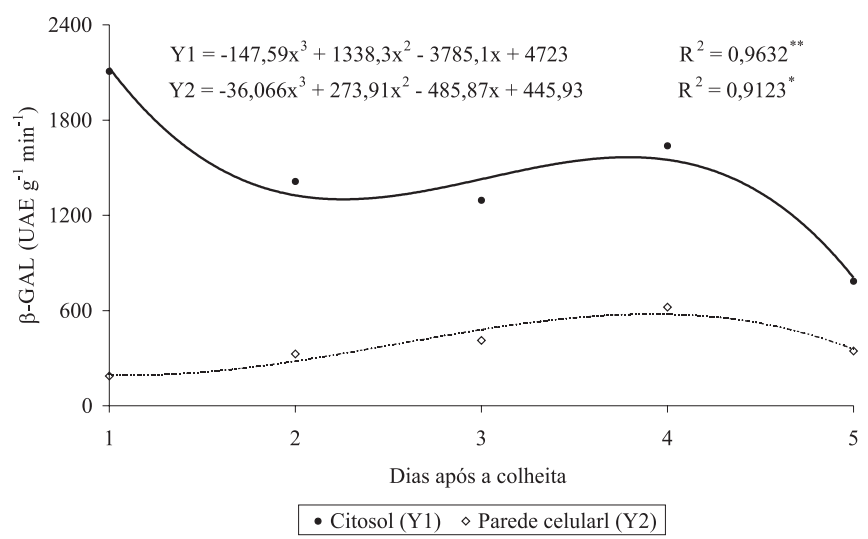

Figura 6. Atividade de beta-galactosidases ( $\beta$-GAL), extraídas do citosol e da parede celular, de graviola Crioula, durante a maturação à temperatura ambiente (26,3 $\pm 0,6^{\circ} \mathrm{C}$ e $88 \pm 12 \%$ UR).
Segundo Ali et al. (2004), em razão da complexidade da estrutura da parede celular, é improvável que uma enzima, em particular, seja capaz de modificá-la significativamente e responder pelo amaciamento. Uma ação coletiva e sinergística de várias enzimas seria necessária para promover mudanças texturais relevantes (Giovannoni, 2001; Ali et al., 2004; Mwaniki et al., 2005). Além disso, mesmo considerando-se a grande importância da atividade das hidrolases da parede celular, para as modificações texturais associadas ao amadurecimento, outros agentes, a exemplo de proteínas não enzimáticas como as expansinas, também contribuem para o processo (Giovannoni, 2001).

Considerando-se que a graviola sofre amaciamento progressivo enquanto amadurece, as enzimas que devem contribuir mais diretamente para o processo são PME, PG (Figura 4) e a beta-GAL de parede celular (Figura 6). A importância das duas últimas deve ser destacada, já que a intensidade com que o amaciamento ocorre diminui com o tempo. Desta forma, espera-se que a atividade das enzimas envolvidas seja reduzida com a evolução do processo. Em um primeiro momento, a PG atuou de modo mais efetivo. Entretanto, a queda precoce de atividade sugere que a beta-GAL de parede celular caracteriza melhor esta transformação.

\section{Conclusões}

1. Nos frutos de Annona muricata L., as reduções nos conteúdos de amido e de pectina total coincidem com período de expressiva atividade, respectivamente, das enzimas amilase e da poligalacturonase e betagalactosidase de parede celular.

2. As modificações mais acentuadas no conteúdo de amido, de pectina total, na solubilização de pectinas e na atividade das enzimas amilase, pectinametilesterase, poligalacturonase e beta-galactosidase de parede celular ocorrem no período do segundo ao quarto dia após a colheita.

\section{Referências}

ALI, Z.M.; CHIN, L.-H.; LAZAN, H. A comparative study on wall degrading enzymes, pectin modifications and softening during ripening of selected tropical fruits. Plant Science, v.167, p.317327, 2004.

ASSOCIATION OF OFFICIAL AGRICULTURAL CHEMISTS (Washington, Estados Unidos). Official methods of analysis of the Association of the Agricultural Chemists. $11^{\text {th }}$ ed. Washington, 1992. 1115p. 
AZIZ, P.A.; YUSOF, S. Physico-chemical characteristics of soursop fruit (Annona muricata) during growth and development. Asean Food Journal, v.9, p.147-150, 1994.

BERNFELD, P. Enzymes in carbohydrate metabolism. In: COLOWICK, S.P.; KAPLAN, N.O. (Ed.). Methods in Enzymology. New York: Academic Press, 1955. v.1, p.149-150.

BLUMENKRANTZ, N.; ASBOE-HANSEN, G. New method for quantitative determination of uronic acids. Analytical Biochemistry, v.54, p.484-489, 1973.

DEY, P.M.; PRIDHAM, J.B. Purification and properties of $\alpha$-galactosidases from Vicia faba seeds. Biochemical Journal, v.113, p.49-55, 1969

GALLEGO, P.P.; ZARRA, I. Cell wall autolysis during kiwifruit development. Annals of Botany, v.81, p.91-96, 1998.

GIOVANNONI, J. Molecular biology of fruit maturation and ripening. Annual Review of Plant Physiology and Plant Molecular Biology, v.52, p.725-749, 2001.

GROSS, K.C.; STARRETT, D.A.; CHEN, H.J. Rhamnogalacturonase, $\alpha$-galactosidase, and $\beta$-galactosidase: potencial roles in fruit softening. Acta Horticulturae, v.398, p.121-130, 1995.

HUBER, D.J.; KARAKURT, Y.; JEONG, J. Pectin degradation in ripening and wounded fruits. Revista Brasileira de Fisiologia Vegetal, v.13, p.224-241, 2001.

IMSABAI, W.; KETSA, S.; DOORN, W.G. van. Effect of temperature on softening and the activities of polygalacturonase and pectinesterase in durian fruit. Postharvest Biology and Technology, v.26, p.347-351, 2002.

IRVING, D.E.; SHINGLETON, G.J.; HURST, P.L. Starch degradation in buttercup squash (Cucurbita maxima). Journal of the American Society for Horticultural Science, v.124, p.587590, 1999

JEN, J.J.; ROBINSON, M.L.P. Pectolytic enzymes in sweet bell peppers (Capsicum annuum L.). Journal of Food Science, v.49, p.1045-1087, 1984.

JOHNSTON, J.W.; HEWETT, E.W.; BANKS, N.H.; HARKER, F.R.; HERTOG, M.L.A.T.M. Physical change in apple texture with fruit temperature: effects of cultivar and time in storage. Postharvest Biology and Technology, v.23, p.13-21, 2001.

KARAKURT, Y.; HUBER, D.J. Activities of several membrane and cell-wall hydrolases, ethylene biosynthetic enzymes, and cell wall polyuronide degradation during low-temperature storage of intact and fresh-cut papaya (Carica papaya) fruit. Postharvest Biology and Technology, v.28, p.219-229, 2003.

KETSA, S.; DAENGKANIT, T. Firmness and activities of polygalacturonase, pectinesterase, $\beta$-galactosidase and cellulase in ripening durian harvested at different stages of maturity. Scientia Horticulturae, v.80, p.181-188, 1999.

KHADER, S.E.S.A. Effect of gibberellic acid and vapor gard on ripening amylase and peroxidase activities and quality of mango fruits during storage. Journal of Horticultural Science, v.67, p.855860, 1992.

KITAGAWA, Y.; KANAYAMA, Y.; YAMAKI, S. Isolation of $\beta$-galactosidase fractions from Japanese pear: activity against native cell wall polysaccharides. Physiologia Plantarum, v.93, p.545-550, 1995.

LIMA, M.A.C. de; ALVES, R.E.; FILGUEIRAS, H.A.C.; ENÉASFILHO, J. Comportamento respiratório e qualidade pós-colheita de graviola (Annona muricata L.) Morada sob temperatura ambiente. Revista Brasileira de Fruticultura, v.25, p.49-52, 2003.

McCREADY, R.M.; McCOMB, E.A. Extraction and determination of total pectic materials in fruits. Analytical Chemistry, v.24, p.1986-1988, 1952.

MILLER, G.L. Use of dinitrosalicylic acid reagent for determination of reducing sugars. Analytical Chemistry, v.31, p.426-428, 1959.

MORGUTTI, S.; NEGRINI, N.; MIGNANI, I.; BASSI, D.; COCUCCI, M. Flesh softening and phosphorylation of soluble polypeptides in relation to ethylene production in Prunus persica fruits with different ripening pattern. Acta Horticulturae, v.682, p.155-162, 2005.

MOSCA, J.L.; ALVES, R.E.; FILGUEIRAS, H.A.C.; OLIVEIRA, J.F. Determination of harvest index for soursop fruits (Annona muricata L.). In: CONGRESO INTERNACIONAL DE ANONACEAS, 1., 1997, Chapingo. Memorias. Chapingo: Universidad Autónoma Chapingo, 1997. p.315-322.

MWANIKI, M.W.; MATHOOKO, F.M.; MAATSUZAKI, M.; HIWASA, K.; TATEISHI, A.; USHIJIMA, K.; NAKANO, R.; INABA, A.; KUBO, Y. Expression characteristics of seven members of the $\beta$-galactosidase gene family in 'La France' pear (Pyrus communis L.) fruit during growth and their regulation by 1-methylcyclopropene during postharvest ripening. Posthavest Biology and Technology, v.36, p.253-263, 2005.

PURGATTO, E.; LAJOLO, F.M.; NASCIMENTO, J.R.O. do; CORDENUNSI, B.R. Inhibition of $\beta$-amylase activity, starch degradation and sucrose formation by indole-3-acetic acid during banana ripening. Planta, v.212, p.823-828, 2001.

RAMOS, V.H.V. A potencialidade da gravioleira no Cerrado. In: PINTO, A.C.Q. A cultura da graviola. Fortaleza: Sindifruta/ Instituto Frutal, 1999. p.42-58.

SÃO-JOSÉ, A.R.; ANGEL, D.N.; BONFIM, M.P.; REBOUÇAS, T.N.H. Cultivo da graviola. In: SEMANA INTERNACIONAL DE FRUTICULTURAE AGROINDÚSTRIA, 7., 2000, Fortaleza. Cursos. Fortaleza: Sindifruta, Instituto Frutal, 2000. 35p. 1 CD-ROM.

SOH, C.-P.; ALI, Z.M.; LAZAN, H. Characterisation of an $\alpha$-galactosidase with potential relevance to ripening related texture changes. Phytochemistry, v.67, p.242-254, 2006.

WILLS, R.; McGLASSON, B.; GRAHAM, D.; JOYCE, D. Postharvest: an introduction to the physiology \& handling of fruit, vegetables \& ornamentals. $4^{\text {th }}$ ed. Wallingford: New South Wales University Press, 1998. 262p.

Recebido em 3 de abril de 2006 e aprovado em 20 de setembro de 2006 